\title{
CKD-602, a camptothecin derivative, inhibits proliferation and induces apoptosis in glioma cell lines
}

\author{
YOUNG-YIM KIM ${ }^{1,2}$, CHUL-KEE PARK ${ }^{1,3}$, SEUNG-KI KIM ${ }^{1,2}$, JI-HOON PHI $^{1,2}$, \\ JIN-HYUN KIM ${ }^{4}$, CHAE-YONG KIM ${ }^{1,5}$, KYU-CHANG WANG ${ }^{1,2}$ and BYUNG-KYU CHO ${ }^{1,2}$ \\ ${ }^{1}$ Department of Neurosurgery, Seoul National University College of Medicine; \\ ${ }^{2}$ Clinical Research Institute; ${ }^{3}$ Cancer Research Institute, Seoul National University Hospital, Seoul; \\ ${ }^{4}$ Clinical Research Institute, Gyeongsang National University Hospital, Gyeongnam, Jinju; \\ ${ }^{5}$ Clinical Neuroscience Center, Seoul National University Bundang Hospital, Gyeonggi-do, Korea
}

Received February 25, 2009; Accepted April 2, 2009

DOI: $10.3892 /$ or_00000369

\begin{abstract}
CKD-602 7-[2-( $N$-isopropylamino)ethyl]-(20S)camptothecin, belotecan) is a synthetic water-soluble camptothecin derivative and topoisomerase inhibitor that has been shown to have clinical anticancer effect against ovarian and lung cancer. We studied its anticancer effects on four human glioma cell lines, U87 MG, U343 MG, U251 MG and LN229. Cell viability was quantified by a modified 2-(2methoxy-4-nitropheyl)-3-(4-nitropheyl)-5-(2,4-disulfophenyl) $-2 \mathrm{H}$-tetrazolium, monosodium salt and significant time- and dose-dependent cytotoxicity was observed in all cell lines. Susceptibility to CKD-602 at $48 \mathrm{~h}$ after treatment varied among the four cell lines and their $\mathrm{IC}_{50}$ value was as follows: $9.07 \mathrm{nM}(95 \%$ CI $0.18-37.42)$ for $\mathrm{LN} 229,14.57 \mathrm{nM}$ (95\% CI 0.86-47.33) for U251 MG, $29.13 \mathrm{nM}(95 \%$ CI 0.35-101.23) for U343 MG, and $84.66 \mathrm{nM}$ (95\% CI 34.63-148.25) for U87 MG. CKD-602 induced cell cycle arrest at G2 phase and produced antiproliferative activity and apoptosis in all cell lines. Thus, CKD-602 showed a significant anticancer effect on glioma cells in vitro and is a promising candidate for further studies on malignant gliomas.
\end{abstract}

\section{Introduction}

Patients with high-grade gliomas have a disappointing survival rate of one year, despite recent advances in best standard therapies, including surgical resection, radiation and new chemotherapeutic agents (1). High-grade gliomas comprise a biologically heterogeneous set of tumors with diverse therapeutic responses to different kinds of anticancer agents.

Correspondence to: Dr Byung-Kyu Cho, Department of Neurosurgery, Seoul National University College of Medicine, 101 Daehangno, Jongno-gu, Seoul 110-744, Korea

E-mail: bkcho@snu.ac.kr

Key words: belotecan, camptothecin analogue, CKD-602, malignant glioma, topoisomerase 1 inhibitor
Moreover, these tumors tend to have resistance to prolonged use of the agents, so other drugs need to be evaluated; the development of effective chemotherapeutic agents in various aspects of drug resistance mechanisms and the investigation of effective targeting agents are important and challenging medical problems.

Topoisomerase inhibitors are a class of agents that interfere with DNA 'unwinding' during DNA replication and RNA transcription. They stabilize DNA-topoisomerase complexes through non-covalent interactions to yield enzyme-linked DNA breaks (2). The prolonged exposure of replicating cells to these agents produces lethal DNA breaks that can trigger apoptosis (3). Various kinds of topoisomerase I inhibitors, most of them camptothecin derivatives, have been developed and show significant anticancer effects in vitro $(4,5)$ and in vivo $(6,7)$. Camptothecin is a plant alkaloid isolated from Camptotheca acuminate that shows high anticancer activity (8). Despite its highly potent anticancer effects, the clinical use of camptothecin sodium is hampered by poor solubility and unpredictable toxicities such as hemorrhagic cystitis, myelosuppression and diarrhea (9-11). With the aim of overcoming these limiting factors, a search for structural analogues of camptothecin has been conducted. This resulted in the discovery of a number of camptothecin analogues, such as CPT-11 and topotecan, with better aqueous solubility and bioavailability (12). These show high clinical efficacy in treating human neoplasms such as colorectal cancer, ovarian cancer and leukemia $(13,14)$. CPT-11 and topotecan also showed efficacy in treating patients with brain tumors, especially when combined with other agents, although the study results are not decisive $(15,16)$. However, poor efficacy as a single agent and he reported major toxicities such as CPT-11-induced colitis or interstitial pneumonia are potential limitations for their further clinical use $(17,18)$. CKD-602, 7-[2-( $N$-isopropylamino)ethyl]-(20S)-camptothecin (belotecan, Chong Kun Dang Pharmaceutical Corporation, Seoul, Korea), is a new synthetic water-soluble camptothecin analogue (19). Clinical trials showed improved toxicity profiles and broad antitumor activity against various human tumor cells, with greater potency than CPT-11 and topotecan $(20,21)$. 
In this study, we evaluated the potential anticancer activity of CKD-602 in vitro using human glioma cell lines and evaluated its feasibility as an anticancer agent for treating patients with malignant gliomas.

\section{Materials and methods}

Reagents. CKD-602 is a semisynthetic analogue of camptothecin containing a 2 -( $N$-isopropylamino) ethyl group linkage at position $\mathrm{C}-7$ of the camptothecin ring $(22,23)$. It stabilizes the complex formed between topoisomerase I and DNA, thereby preventing the religation of DNA breaks. This leads to an inhibition of DNA replication and triggers apoptotic cell death (24). For this study, we used $10 \mathrm{mM}$ stock solutions of CKD-602 dissolved in distilled water. CKD-602 was a gift from Chong Kun Dang Pharmaceutical Corporation.

Cell culture. Human glioblastoma cell lines were obtained from the Korea Cell Line Bank (U87 MG and U251 MG, Seoul, Korea) and purchased from ATCC (U343 MG, LN229, American Type Culture Collection, Manassas, VA, USA). U87 MG and U343 MG cells express wild-type $p 53$, whereas U251 MG and LN229 cells harbor a p53 mutation (25). The cells were cultured in Dulbecco's modified Eagle's medium (DMEM; welGene, Daegu, Korea) supplemented with $10 \%$ inactivated fetal bovine serum (Invitrogen, Grand Island, $\mathrm{NY}, \mathrm{USA}$ ) and $10 \mathrm{mg} / \mathrm{ml}$ of an antibiotic-antimycotic agent (Invitrogen) at $37^{\circ} \mathrm{C}$ in air with $5 \% \mathrm{CO}_{2}$.

Cell viability. The cytotoxic effect of CKD-602 was quantified using a modified 2-(2-methoxy-4-nitropheyl)-3-(4-nitropheyl) -5-(2, 4-disulfophenyl)-2H-tetrazolium, monosodium salt (CCK-8; Dojindo Molecular Technologies Inc., Gaithersburg, MD, USA). Target cells were plated in 96-well plates (Techno Plastic Products) at a density of $2 \times 10^{3}$ cells/well $(100 \mu \mathrm{l})$ and incubated overnight for attachment. In each experimental set, cells were plated in quadruplicate and were treated with different concentrations $(0.05,0.1,0.2,0.5,1,2,5 \mu \mathrm{M})$ of CKD-602 for 24, 48 and $72 \mathrm{~h}$. CCK-8 reagent was added for colorimetric reactions up to a final concentration of $10 \%(\mathrm{v} / \mathrm{v})$. Plates were incubated another $3 \mathrm{~h}$ at $37^{\circ} \mathrm{C}$. Extinction was measured on an ELISA reader at $450 \mathrm{~nm}$ (VERSAmax microplate reader, Molecular Devices, CA, USA). Cell survival was calculated according to the following equation: viability $(\%)=\left(\mathrm{OD}_{450[\text { sample }]} / \mathrm{OD}_{450[\text { control] }}\right) \times 100$. The percentage of viable cells was calculated and plotted against drug concentrations. The half maximal $(50 \%)$ inhibitory concentration $\left(\mathrm{IC}_{50}\right)$ value was calculated from the dose-response curve.

BrdU cell proliferation assay. Cells were seeded at $2 \times 10^{3}$ cells/ well in 96-well plates and incubated overnight. They were treated with different concentrations $(0.05,0.1,0.2,0.5,1,2$, $5 \mu \mathrm{M})$ of CKD-602 for $48 \mathrm{~h}$. Cellular proliferations were measured by colorimetric immunoassay based on BrdU incorporation into the cellular DNA following the instructions of the manufacturers (Cell Proliferation ELISA, BrdU kit; Roche Molecular Biochemical, Indianapolis, IN, USA). Briefly, cells were pulsed with BrdU labeling reagent for $3 \mathrm{~h}$, followed by fixation in FixDenat solution for $30 \mathrm{~min}$ at room temperature. Thereafter, cells were incubated with 1:100 dilution of antiBrdU-POD for $1 \mathrm{~h}$ at room temperature. Finally, the immunoreaction was detected by adding the substrate solution and the color developed was read at $370 \mathrm{~nm}$.

Cell cycle analysis. Cells were plated at $2 \times 10^{5} /$ well in 6-well plates for $24 \mathrm{~h}$ before treatment. Cells were treated with different concentrations of CKD-602 for $48 \mathrm{~h}$ based on $\sim 2$-fold of their $\mathrm{IC}_{50}$ values, harvested by centrifugation at 1,200 rpm for 5 min, washed twice in ice-cold PBS, fixed in $70 \%$ ethanol, stored at $4^{\circ} \mathrm{C}$ for a minimum of $1 \mathrm{~h}$, washed with ice-cold PBS and resuspended in a mixture of $200 \mu 1 \mathrm{PBS}$, $20 \mu \mathrm{l}$ RNase (10 mg/ml, Qiagen, Hilden, Germany) and $2 \mu \mathrm{l}$ propidium iodide (PI, $25 \mathrm{mg} / \mathrm{ml}$, Promega, Madison, WI, USA). The cell suspension was passed through a $40 \mu \mathrm{m}$ pore filter to remove undesirable particles and aggregates. Cell cycle position was evaluated by Becton-Dickinson Fluorescence-Activated Cell Sorting (FACScan) using an excitation laser set at $480 \mathrm{~nm}$ and a detection wavelength of 575 nm (Becton-Dickinson, Mountain View, CA, USA). A minimum of 10,000 events/sample was analyzed.

Annexin assay. Apoptosis was quantified using Annexin VFITC apoptosis kit (Pharmigen, San Diego, CA, USA) according to the manufacturer's instructions. Briefly, cells were plated at $2 \times 10^{5} /$ well in two wells of 6 -well plates. Cells were treated with different concentrations of CKD-602 for $48 \mathrm{~h}$ based on $\sim 2$-fold of their $\mathrm{IC}_{50}$ values and harvested by centrifugation at $700 \mathrm{rpm}$ for $5 \mathrm{~min}$. Cell pellets were resuspended in annexin $\mathrm{V}$ binding buffer $(150 \mathrm{mmol} / \mathrm{l} \mathrm{NaCl}$, $18 \mathrm{mmol} / 1 \mathrm{CaCl}_{2}, 10 \mathrm{mmol} / \mathrm{l} \mathrm{HEPES}, 5 \mathrm{mmol} / \mathrm{l} \mathrm{KCl}, 1 \mathrm{mmol} / \mathrm{l}$ $\left.\mathrm{MgCl}_{2}\right)$. FITC-conjugated annexin $\mathrm{V}(1 \mu \mathrm{M} / \mathrm{ml})$ and PI $(50 \mu \mathrm{M} / \mathrm{ml})$ were added to cells and incubated for $30 \mathrm{~min}$ at room temperature in the dark. Analyses were done using a FACScan (Becton-Dickinson). Annexin V- and PI-positive cells were regarded to be apoptotic.

Apoptosis assay. The terminal deoxynucleotidyl transferasemediated dUTP nick-end labeling (TUNEL) assay for apoptosis detection was performed using the Apoptag peroxidase in situ apoptosis detection kit (Intergen Company, Purchase, NY, USA). Briefly, cells were plated at $2 \times 10^{5} /$ well on coverslips in 6 -well plates. Cells were treated with different concentrations of CKD-602 for $48 \mathrm{~h}$ based on $\sim 2$-fold of their $\mathrm{IC}_{50}$ values. The cells were washed with PBS and fixed in $4 \%(\mathrm{w} / \mathrm{v})$ paraformaldehyde in PBS $(\mathrm{pH} 7.4)$ for $10 \mathrm{~min}$ at $4^{\circ} \mathrm{C}$. The fixed cells were then incubated with $3 \%$ $\mathrm{H}_{2} \mathrm{O}_{2}$ in buffer, followed by 10 min proteolytic digestion in prediluted proteinase $\mathrm{K}$. The cells were incubated in equilibration buffer for $2 \mathrm{~min}$, then with digoxigeninconjugated dUTP in a terminal deoxynucleotidyl transferase (TdT)-catalyzed reaction for $60 \mathrm{~min}$ at $37^{\circ} \mathrm{C}$ in a humidified atmosphere and were then immersed in stop/wash buffer for $10 \mathrm{~min}$ at room temperature. The cells were incubated with antidigoxigenin antibody conjugated with peroxidase for $30 \mathrm{~min}$. Color development was done using DAB. The cells were then counterstained with hematoxylin, dehydrated, cleared and coverslipped using a xylene-based mounting medium. TUNEL-positive cells were counted in 10 randomly selected fields. 
A

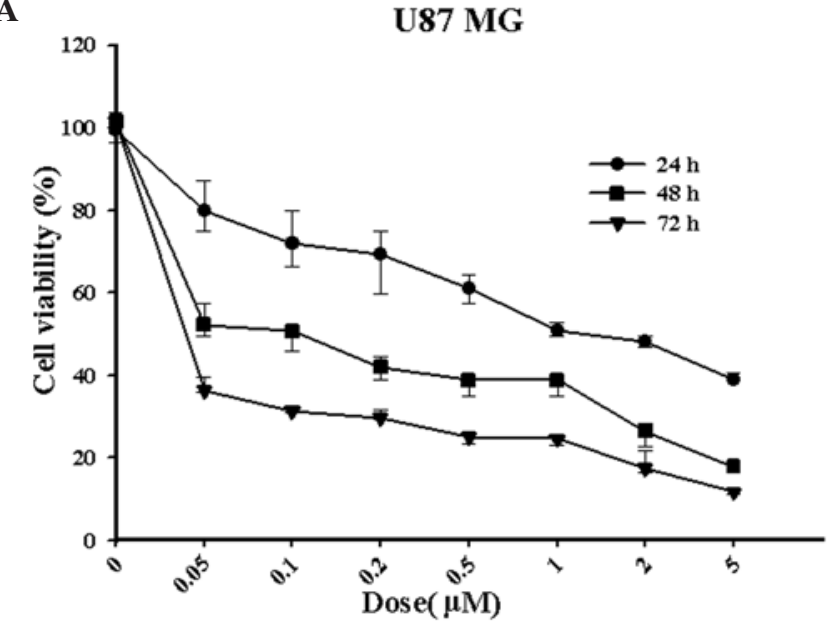

U251 MG

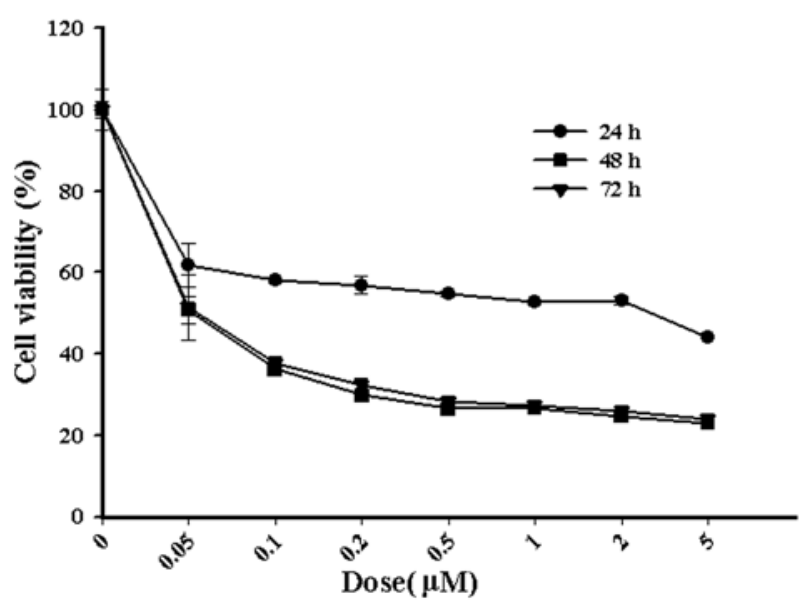

B

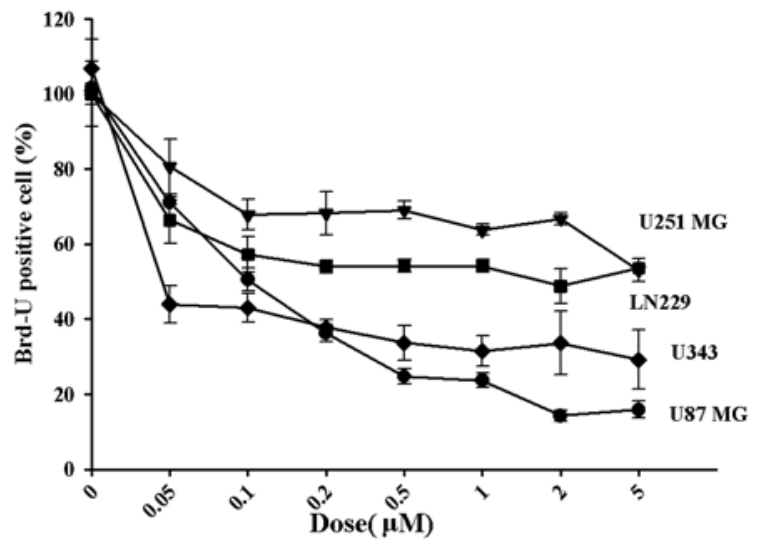

Figure 1. (A) Cell viability after CKD-602 treatment. All cell lines showed significant reduction of viability with time $(\mathrm{P}<0.05$, ANOVA) and dose $(\mathrm{P}<0.05$, ANOVA). Data are expressed as the mean percentage of viable cells \pm SD. (B) CKD-602 treatment inhibited cell proliferation in a dosedependent manner. Mean percentages of proliferative cells observed after BrdU staining are shown ( $\mathrm{P}<0.05$, ANOVA).

Statistics. The data are expressed as the mean \pm SD and as 95\% confidence intervals. Probit regression analysis was performed to determine the $\mathrm{IC}_{50}$ for cell viability analysis and repeated measures ANOVA was used to test for time- or
U343

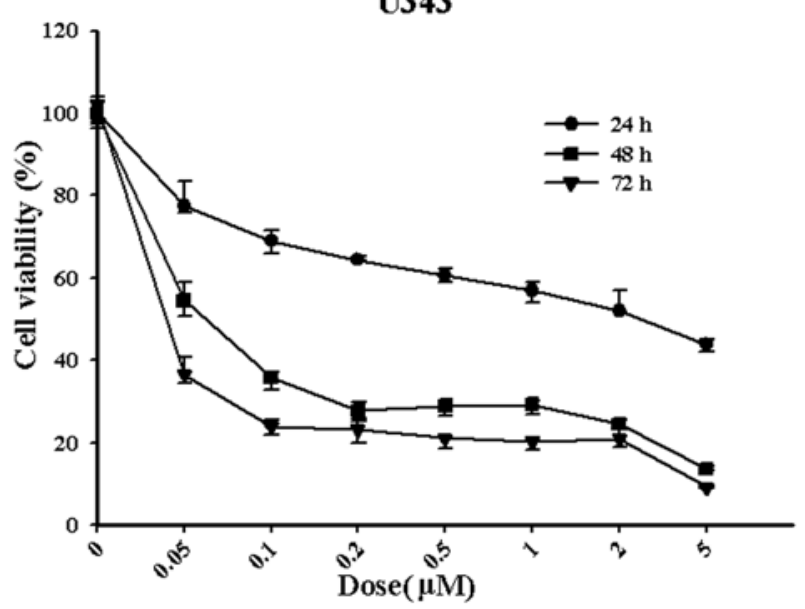

LN 229

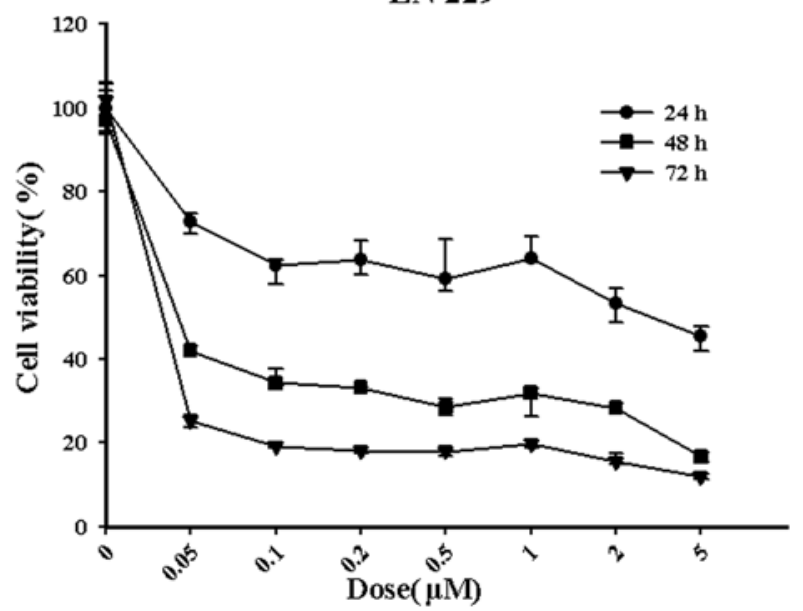

dose-dependency of cytotoxicity. The antiproliferation effect of CKD-602 was assessed using ANOVA. The mean values of cell number distribution expressed in flow cytometry used in cell cycle analysis, apoptosis assay and TUNEL staining were compared using Student's t-test. Statistical significance was accepted at $\mathrm{P}<0.05$.

\section{Results}

CKD-602 induced time- and dose-dependent cytotoxicity and proliferation inhibition. Using the cell viability assay, CKD-602 showed significant cytotoxic effect on all cell lines in time- $(\mathrm{P}<0.05)$ and dose-dependent $(\mathrm{P}<0.05)$ manner (Fig. 1A). The $\mathrm{IC}_{50}$ (50\% inhibition concentration of cell viability) values were $84.66 \mathrm{nM}(95 \%$ CI 34.63-148.25) for U87 MG cells, $29.13 \mathrm{nM}$ (95\% CI 0.35-101.23) for U343 MG, $14.57 \mathrm{nM}(95 \%$ CI 0.86-47.33) for U251 MG cells and $9.07 \mathrm{nM}$ (95\% CI 0.18-37.42) for LN229 cells at $48 \mathrm{~h}$ after treatment.

The antiproliferative effect of CKD-602 was calculated from BrdU staining after $48 \mathrm{~h}$ exposure to CKD-602 at various concentrations (Fig. 1B). CKD-602 inhibited the proliferation of cells in a dose-dependent manner in all cell lines. U87 MG and U343 MG cells were more sensitive than U251 MG and LN229 cells after CKD-602 treatment with regard to proliferation inhibition $(\mathrm{P}<0.05)$. 

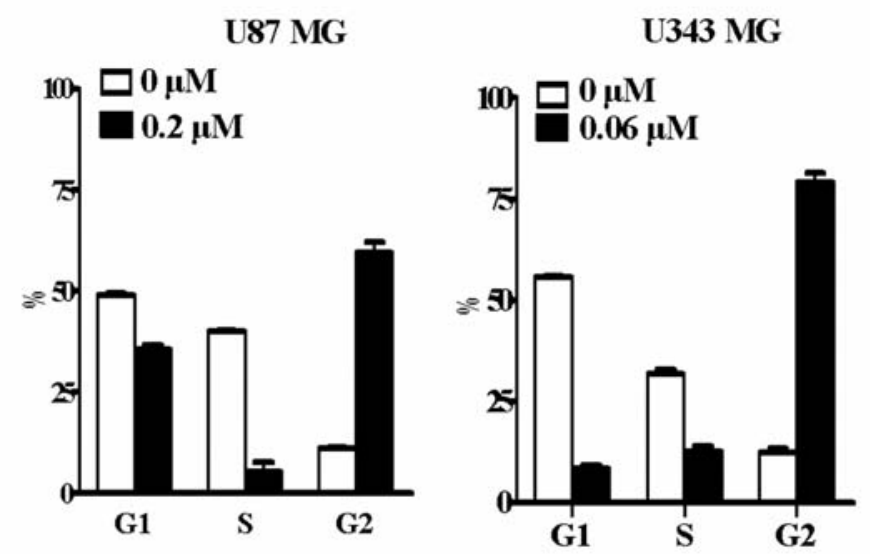

U87 MG

\begin{tabular}{ccrc}
\hline & $\boldsymbol{0} \boldsymbol{\mu M}$ & \multicolumn{1}{c}{$\mathbf{0 . 2} \boldsymbol{\mu M}$} & P value \\
\hline G1 & $48.98 \pm 1.02$ & $35.77 \pm 1.72$ & 0.00 \\
S & $39.98 \pm 0.66$ & $2.70 \pm 3.79$ & 0.00 \\
G2 & $11.05 \pm 0.51$ & $61.68 \pm 3.85$ & 0.00 \\
\hline
\end{tabular}

\section{U343 MG}

\begin{tabular}{ccrc}
\hline & $\mathbf{0} \boldsymbol{\mu M}$ & \multicolumn{1}{c}{$\mathbf{0 . 0 6} \boldsymbol{\mu M}$} & P value \\
\hline G1 & $55.71 \pm 0.32$ & $8.40 \pm 1.58$ & 0.00 \\
S & $31.84 \pm 1.65$ & $12.50 \pm 2.48$ & 0.00 \\
G2 & $12.44 \pm 1.42$ & $79.10 \pm 4.05$ & 0.00 \\
\hline
\end{tabular}

U251 MG
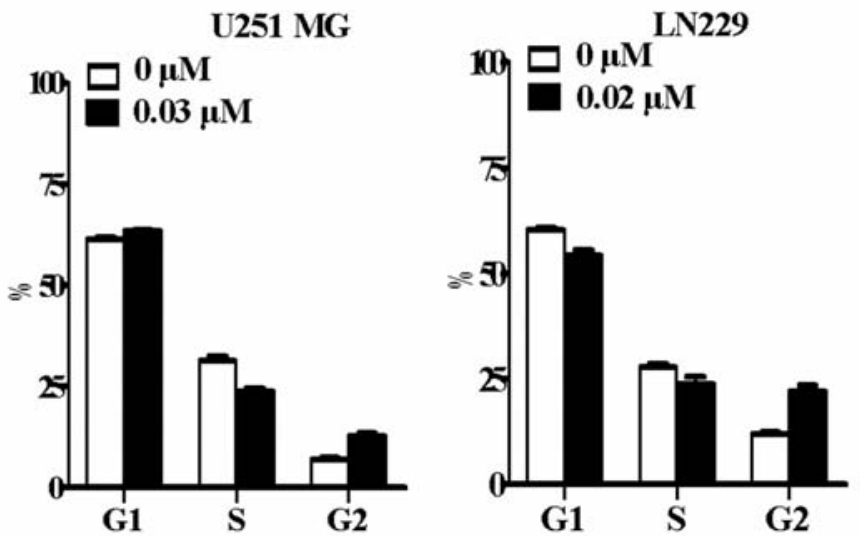

\begin{tabular}{|c|c|c|c|}
\hline & $0 \mu \mathrm{M}$ & $0.03 \mu \mathrm{M}$ & P value \\
\hline G1 & $61.41 \pm 0.75$ & $63.37 \pm 0.56$ & 0.02 \\
\hline $\mathbf{S}$ & $31.56 \pm 1.41$ & $23.85 \pm 1.21$ & 0.00 \\
\hline G2 & $7.03 \pm 0.76$ & $12.78 \pm 1.25$ & 0.00 \\
\hline \multicolumn{4}{|c|}{ LN229 } \\
\hline & $0 \mu \mathrm{M}$ & $0.02 \mu \mathrm{M}$ & $P$ value \\
\hline G1 & $60.34 \pm 0.87$ & $54.21 \pm 2.36$ & 0.01 \\
\hline $\mathbf{S}$ & $27.74 \pm 1.51$ & $23.80 \pm 3.20$ & 0.13 \\
\hline G2 & $11.92 \pm 0.87$ & $21.98 \pm 2.69$ & 0.00 \\
\hline
\end{tabular}

Figure 2. Cell cycle analysis using flow cytometry analysis of glioma cells treated without or with CKD-602 treatment. All cell lines showed G2 phase arrest. Cells were harvested at $48 \mathrm{~h}$ and analyzed for DNA content by propidium iodide staining.

CKD-602 induces cell cycle arrest at G2 phase and apoptosis. Cell cycle analysis was performed after treatment with different concentrations (U87 MG; $0.2 \mu \mathrm{M}$, U343 MG; $0.06 \mu \mathrm{M}$, U251 MG; $0.03 \mu \mathrm{M}, \mathrm{LN} 229 ; 0.02 \mu \mathrm{M}$, respectively) of CKD-602 for $48 \mathrm{~h}$ in each cell line. CKD-602 induced G2 cell accumulation in all cell lines, and the block of G2 phase was higher in U87 MG and U343 MG than in U251 MG and LN229 (Fig. 2). We also observed apoptotic death in all cell lines in different concentrations (U87 MG; $0.2 \mu \mathrm{M}$, U343 $\mathrm{MG} ; 0.06 \mu \mathrm{M}$, U251 MG; $0.03 \mu \mathrm{M}$, LN229; $0.02 \mu \mathrm{M}$ respectively) of CKD-602 for $48 \mathrm{~h}$ by Annexin $\mathrm{V}$ and TUNEL staining. FITC-conjugated Annexin V signals demonstrated a significant increase in apoptotic cells after CKD-602 treatment $(\mathrm{P}<0.05$, Fig. 3). TUNEL staining also showed that the numbers of apoptotic nuclei increased after CKD-602 treatment. After CKD-602 treatment, 44.25 $\pm 1.31 \%$ in the U87 MG cells, $40.87 \pm 5.30 \%$ in the U343 MG cells, $9.93 \pm 1.59 \%$ in the U251 MG cells and $17.62 \pm 4.73 \%$ in the LN229 cells were positive at TUNEL staining (Fig. 4).

\section{Discussion}

CKD-602 is a potent topoisomerase I inhibitor that successfully overcomes the poor water solubility and toxicity of its parent drug, camptothecin (28). It showed potent anticancer activity against various tumor cells in vitro and in vivo in animal models (19-21). In phase I and II studies for solid cancers, CKD-602 showed significant anticancer activity against ovarian cancer (overall response $45 \%$ ) and small cell lung cancer (overall response 45\%) and dose-limiting toxicity was demonstrated by neutropenia and thrombocytopenia, but not by diarrhea, which is the prototype toxicity of CPT-11 (26-28). Clinical trials including CPT-11 or topotecan for malignant glioma are ongoing and have shown promising results $(29,30)$. Therefore, CKD-602 also appears to have promise in the treatment of patients with gliomas based on its potent anticancer effect, with improved tolerability compared with previous camptothecin derivatives.

In the present study, CKD-602 showed cytotoxicity, causing antiproliferative activity and apoptosis in glioma cell lines in a dose- and time-dependent manner. The cytotoxic effect of CKD-602 was more prominent in the U251 MG and LN229 cell lines with p53 mutation than in the U87 MG and U343 MG cell lines without $p 53$ mutation. The U87 MG and U343 MG cell lines showed more prominent inhibition of proliferation, cell cycle arrest at G2 phase and apoptosis than the U251 MG and LN229 cell lines after CKD-602 treatment. The influence of the $p 53$ gene on the efficacy of topoisomerase inhibitors has been reported with controversy. Wang et al demonstrated that $p 53$ disruption dramatically sensitizes glioblastoma cells to DNA topoisomerase I inhibitormediated apoptosis while wild-type $p 53$ cell lines arrest and develop a senescence-like phenotype after SN-38 treatment (31). In the screening study correlating the effect of anti- 

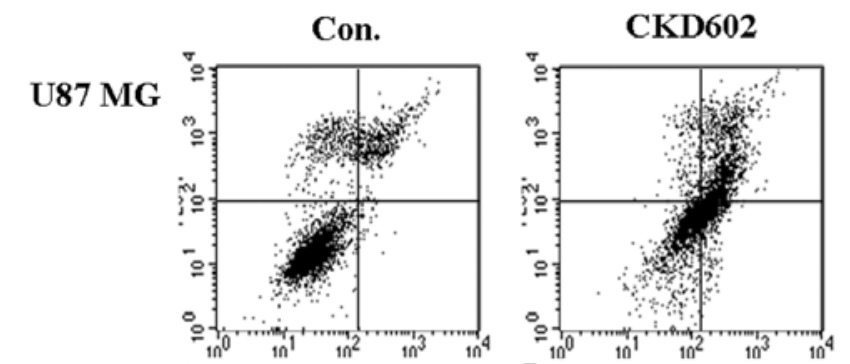

U87 MG

U343 MG
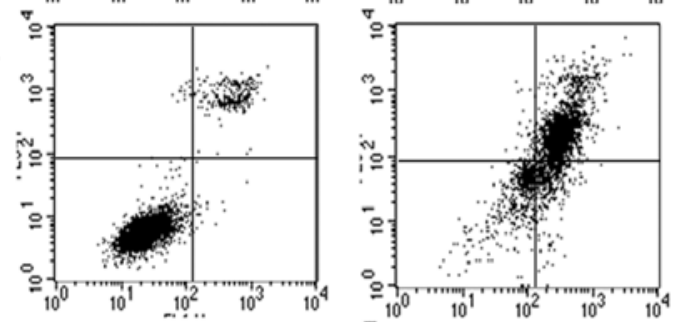

\begin{tabular}{lrrc}
\hline $\mathbf{\%}$ & \multicolumn{1}{c}{$\boldsymbol{0} \boldsymbol{\mu M}$} & \multicolumn{1}{c}{$\mathbf{0 . 2} \boldsymbol{\mu M}$} & P value \\
\hline Viable & $73.84 \pm 2.34$ & $33.00 \pm 5.40$ & 0.00 \\
apoptotic & $16.61 \pm 0.69$ & $62.51 \pm 6.68$ & 0.00 \\
necrotic & $9.55 \pm 2.40$ & $4.48 \pm 1.28$ & 0.01 \\
\hline
\end{tabular}

U343 MG

\begin{tabular}{lrrc}
\hline$\%$ & \multicolumn{1}{c}{$\boldsymbol{\mu} \mathbf{M}$} & \multicolumn{1}{c}{$\mathbf{0 . 0 6} \boldsymbol{\mu M}$} & Pvalue \\
\hline Viable & $89.97 \pm 1.15$ & $14.79 \pm 1.52$ & 0.00 \\
apoptotic & $9.52 \pm 0.92$ & $85.30 \pm 1.68$ & 0.00 \\
necrotic & $0.52 \pm 0.23$ & $1.41 \pm 0.26$ & 0.00 \\
\hline
\end{tabular}
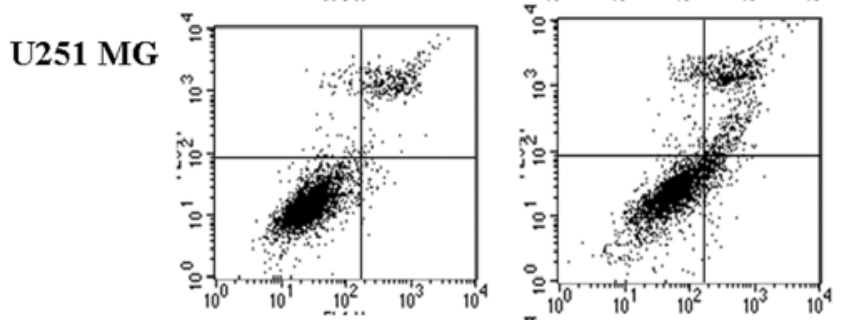

U251 MG

\begin{tabular}{lccc}
\hline \% & $\mathbf{0 ~} \boldsymbol{\mu M}$ & $\mathbf{0 . 0 3} \boldsymbol{\mu M}$ & P value \\
\hline Viable & $85.32 \pm 1.63$ & $68.85 \pm 1.70$ & 0.00 \\
apoptotic & $11.60 \pm 0.77$ & $27.34 \pm 1.72$ & 0.00 \\
necrotic & $9.11 \pm 4.41$ & $3.82 \pm 0.12$ & 0.50 \\
\hline
\end{tabular}

LN229
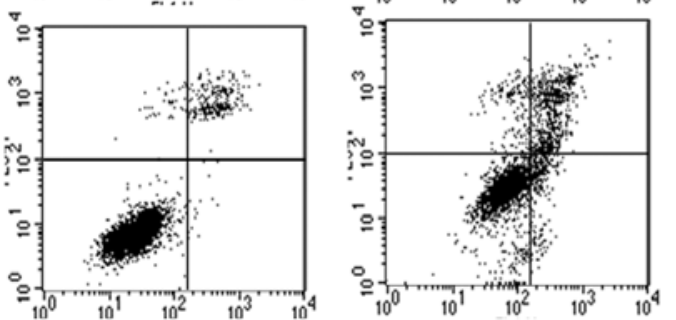

LN229

\begin{tabular}{lrrc}
\hline $\mathbf{\%}$ & \multicolumn{1}{c}{$\boldsymbol{0} \boldsymbol{\mu M}$} & $\mathbf{0 . 0 2} \boldsymbol{\mu M}$ & P value \\
\hline Viable & $91.76 \pm 0.53$ & $59.32 \pm 9.29$ & 0.00 \\
apoptotic & $7.35 \pm 0.29$ & $33.99 \pm 12.98$ & 0.01 \\
necrotic & $0.89 \pm 0.34$ & $3.82 \pm 0.83$ & 0.00 \\
\hline
\end{tabular}

Figure 3. Induction of apoptosis and necrosis in glioma cells after CKD-602 treatment for $48 \mathrm{~h}$ demonstrated by FITC-conjugated Annexin V and propidium iodide staining. Significant increases in apoptotic cells after CKD-602 treatment are shown.

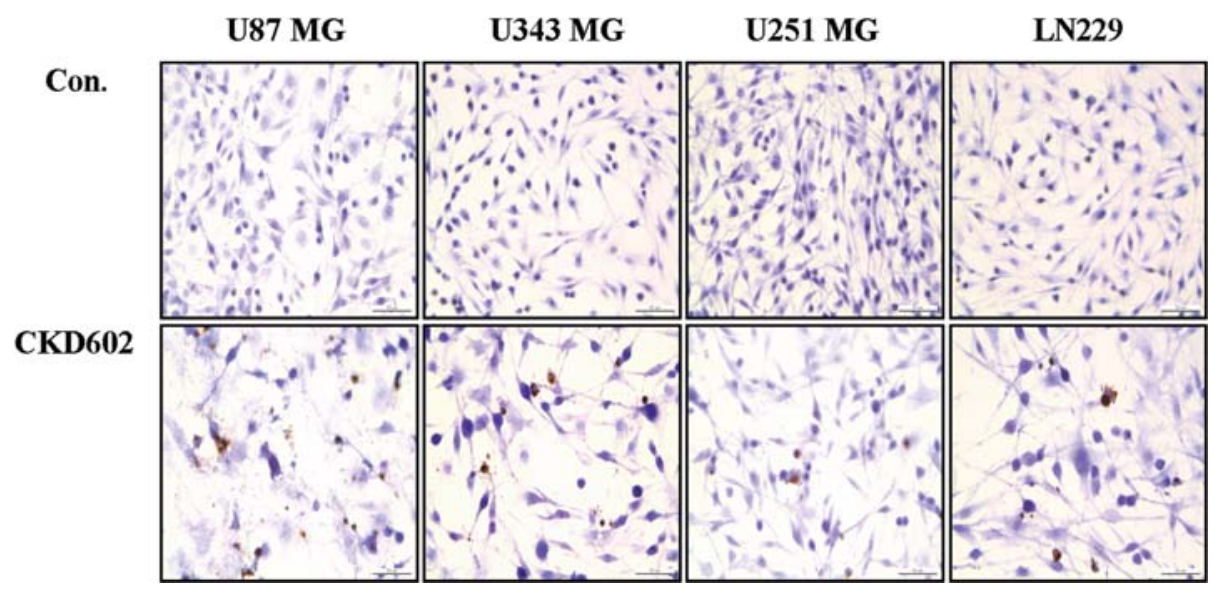

Figure 4. Apoptotic cells were observed after CKD-602 treatment for $48 \mathrm{~h}$ following terminal deoxynucleotidyl transferase-mediated dUTP nick-end labeling (TUNEL) staining (x400 original magnification).

cancer drugs in cell lines with their p53 status, mutant p53 sequence tended to exhibit less growth inhibition than the wild-type $p 53$ cell lines when treated with the majority of clinically used anticancer agents including topoisomerase I inhibitor (32). However, there are recent studies denying the role of p53 in differential susceptibility to topoisomerase I inhibitor $(33,34)$. Based on this evidence, the relationship between $p 53$ status and the effect of topoisomerase I inhibitors, including CKD-602, requires further evaluation and study. 
Our result suggest that CKD-602 blocks the progression of cell cycles in $\mathrm{G} 2$ phase cells, leading to apoptosis and that CKD-602 induced more increase in the percentage of cells in G2 phases in U87 MG and U343 MG than in U252 MG and LN229. This findings coincide with other studies with CPT-11. Nakatsu et al (35) reported a decrease in the percentage of cells in $\mathrm{G} 1$ phase and an increase in the percentage of cells in $\mathrm{S}$ and G2 phases in human glioblastoma GB-1 cells and U87 MG cells after treatment with SN-38. Moreover, CPT induced cytotoxicity to both U251 MG and DAOY cells and produced prolonged G2 delay in these cells (36). This evidence implies that the CKD-602 shares its mechanism of action with its prototype, CPT- 11 .

In conclusion, CKD-602 showed in vitro anticancer efficacy against human malignant glioma cell lines. This potent anticancer activity suggests that CKD-602 is a promising candidate for treating patients with malignant gliomas. Our results provide a rationale for further evaluation of CKD-602 for glioblastomas by in vivo and clinical studies.

\section{Acknowledgements}

This study received grant support from the National R\&D Program for Cancer Control, Ministry of Health \& Welfare, Grant no. 0520300 (B-K. Cho), Korea Science and Engineering Foundation (KOSEF) Grant no. R01-2008000-20268-0 (S-K. Kim). We thank Chong Kun Dang Pharmaceutical Corporation for providing CKD-602.

\section{References}

1. Stupp R, Mason WP, van den Bent M J, et al: Radiotherapy plus concomitant and adjuvant temozolomide for glioblastoma. $\mathrm{N}$ Engl J Med 352: 987-996, 2005.

2. Gomez-Manzano C, Alonso MM, Alfred Yung WK, et al: Delta-24 increases the expression and activity of topoisomerase I and enhances the antiglioma effect of irinotecan. Clin Cancer Res 12: $556-562,2006$

3. D'Arpa P, Beardmore C and Lui F: Involvement of nucleic acid synthesis in cell killing mechanisms of topoisomerase poisons. Cancer Res 50: 6919-6924, 1990.

4. Friedman HS, Keir ST and Houghton PJ: The emerging role of irinotecan (CPT-11) in the treatment of malignant glioma in brain tumors. Cancer 97: 2359-2362, 2003

5. Matsumoto Y, Fujiwara T, Honjo Y, Sasaoka N, Tsuchida T and Nagao S: Quantitative analysis of DNA-topoisomerae-I activity in human and rat glioma: characterization and mechanism of resistance to anti-topoisomerase chemical, camptothecin- 11 . J Surg Oncol 53: 97-103, 1993.

6. Thompson J, George EO, Poquette CA, et al: Synergy of topotecan in combination with vincristine for treatment of pediatric solid tumor xenografts. Clin Cancer Res 5: 3617-3631, 1999

7. Bissery MC, Vrignaud P, Lavalle F and Chabot GG: Experimental antitumor activity and pharmacokinetics of the camptothecin analog irinotecan (CPT-11) in mice. Anticancer Drugs 7: 437-460, 1996.

8. Wall ME, Wani MC, Cook CE, Palmer KH, McPhail AT and Sim GA: Plant antitumor agents. I. The isolation and structure of camptothecin, a novel alkaloidal leukemia and tumor inhibitor from Camptotheca acuminate. J Am Chem Soc 88: 3888-3890, 1966.

9. Gottlieb JA, Guarino AM, Call JB Oliverio VT and Block JB: Preliminary pharmacologic and clinical evaluation of camptothecin sodium. Cancer Chemother Rep 54: 461-467, 1970.
10. Muggia FM, Creven PJ, Hansen HH, Cohen MH and Selawry OS: Phase I clinical trial of weekly and daily treatment with camptothecin. Cancer Chemother Rep 56: 515-521, 1972.

11. Moertel CG, Schutt AJ, Reitmeier RJ and Hahn RG: Phase II study of camptothecin in the treatment of advanced gastrointestinal cancer. Cancer Chemother Rep 56: 95-101, 1972.

12. Kolimannsberger C, Mross K, Jakob A, Kanz L and Bokemeyer C: Topotecan - a novel topoisomerase I inhibitor: pharmacology and clinical experience. Oncology 56: 1-12, 1999.

13. Mathijssen RH, Loos WJ, Verweij J and Sparreboom A: Pharmacology of topoisomerase I inhibitors irinotecan (CPT-11) and topotecan. Curr Cancer Drug Targets 2: 103-123, 2002.

14. Josson E, Dhar S, Josson B, Nygren P, Graf W and Larsson, R: Differential activity of topotecan, irinotecan and SN-38 in fresh human tumour cells but not in cell lines. Eur J Cancer 36: 2120-2217, 2000.

15. Reardon DA, Quinn JA, Rich JN, et al: Phase 2 trial of BCNU plus irinotecan in adults with malignant glioma. Neurooncology 6: 134-144, 2004

16. Klaute G, Schütze M, Bombor I, Benecke R, Piek J and Fietkau R: Concurrent chemoradiotherapy and adjuvant chemotherapy with Topotecan for patients with glioblastoma multiforme. J Neurooncol 77: 199-205, 2006.

17. Raymond E, Fabbro M, Boige V, et al: Multicentre phase II study and pharmacokinetic analysis of irinotecan in chemotherapy-naive patients with glioblastoma. Ann Oncol 14: 603-614, 2003.

18. Michielin O, Udry E, Périard D, Matzinger O, Lobrinus JA and Stupp R: Irinotecan-induced interstitial pneumonia. Lancet Oncol 5: 322-324, 2004.

19. Lee JH, Lee JM, Kim JK, et al: Antitumor activity of 7-[2-(Nisopropylamino) ethyl]-(20S)-camptothecin, CKD-602 as a potent DNA topoisomerase I inhibitor. Arch Pharm Res 21: 581-590, 1998.

20. Lee JH, Lee JM, Lim KH, Kim JK, Ahn SK, Bang YJ and Hong CI: Preclinical and phase I clinical studies with CKD-602, a novel camptothecin derivative. Ann NY Acad Sci 922: 324-325, 2000.

21. Kim EJ, Lee RK, Suh JE, Han SS and Kim JK: Safety pharmacology of CKD-602, a novel anticancer agent. Arzneimittel Forschung 53: 272-279, 2003.

22. Jew SS, Kim HJ, Kim MG, Rho EY, Park HG, Kim JK, Han HJ and Lee H: Synthesis and antitumor activity of 7-substituted camptothecin analogues. Bioorg Med Chem Lett 6: 845-848, 1996.

23. Lee JH, Sohn YS, Lee JM, Kim JK, Ahn SK, Jew SS, Park JG, and Hong CI: Antitumor activity of CKD602, a novel camptothecin derivative. Proc Am Assoc Cancer Res 39: 303, 1998.

24. Fassberg J and Stella VJ: A kinetic and mechanistic study of the hydrolysis of camptothecin and some analogues. J Pharm Sci 81: 676-684, 1992.

25. Ishii N, Maier D, Merlo A, Tada M, Sawamura Y, Diserens AC and Van Meir EG: Frequent co-alterations of TP53, p16/ CDKN2A, p14 ARF, PTEN tumor suppressor gene in human glioma cell lines. Brain Path 9: 469-479, 1999.

26. Jung JY, Song SH, Kim TY, Park JH, Jong HS, Im SA, Kim TY, Bang YJ and Kim NK: The synergism between belotecan and cisplatin in Gastric Cancer. Cancer Res Treat 38: 159-167, 2006.

27. HK Kim, YJ Bang, DS Hoe, SG Shin and NK Kim: Phase I trial of CKD-602, a novel camptothecin derivative, in patients with advanced solid tumor. Proc Am Soc Clin Oncol 21 (abstr 393), 2002.

28. Song Y, Seo SS, Bang YJ, Kang SB, Nam JH, Ryu SY, Lee KH, Park SY, Hong CI and Lee HP: Phase II evaluation of CKD-602, a comptothecin analog administered on a 5-day schedule in patients with recurrent or refractory ovarian cancer. Proc Am Soc Clin Oncol 22 (abstr 1877), 2003.

29. Vredenburgh JJ, Desjardins A, Herndon JE, et al: Phase II trial of bevacizumab and irinotecan in recurrent malignant glioma. Clin Cancer Res 15: 1253-1259, 2007.

30. Feun LG, Marini A, Landy H, Markoe A, Heros D, Robles C, Herrera C and Savaraj N: Clinical trial of CPT-11 and VM-26/ VP-16 for patients with recurrent malignant brain tumors. J Neurooncol 82: 177-181, 2007.

31. Wang Y, Zhu S, Cloughesy TF, Liau LM and Mischel PS: p53 disruption profoundly alters the response of human glioblastoma cells to DNA topoisomerase I inhibition. Oncogene 23: 1283-1290, 2004. 
32. O'Connor PM, Jackman J, Bae I, et al: Characterization of p53 tumor suppressor pathway in cell lines of the national cancer institute anticancer drug screen and correlations with the growth-inhibitory potency of 123 anticancer agents. Cancer Res 57: 4285-4300, 1997.

33. Djuzenova CS, Güttler T, Berger S, Katzer A and Flentje M: Differential response of human glioblastoma cell lines to combined camptothecin and ionizing radiation treatment. Cancer Biol Ther 7: 364-373, 2008.

34. Morandi E, Severini C, Quercioli D, et al: Gene expression time-series analysis of camptothecin effects in U87-MG and DBTRG-05 glioblastoma cell lines. Mol Cancer 7: 66, 2008.
35. Nakatsu S, Kondo S, Kondo Y, Yin D, Peterson JW, Kaakaji R, Morimura T, Kikuchi H, Takeuchi J and Barnett GH: Induction of apoptosis in multi-drug resistant (MDR) human glioblastoma cells by SN-38, a metabolite of the camptothecin derivative CPT-11. Cancer Chemother Pharmacol 39: 417-423, 1997.

36. Janss AJ, Levow C, Bernhard EJ, Muschel RJ, McKenna WG, Sutton L and Phillips PC: Caffeine and staurosporine enhance the cytotoxicity of cisplatin camptothecin in human brain tumor cell lines. Exp Cell Res 243: 2-38, 1998. 